http://jmscr.igmpublication.org/home/

ISSN (e)-2347-176x ISSN (p) 2455-0450

crossref DOI: https://dx.doi.org/10.18535/jmscr/v7i7.46

\title{
Periampullary Cancer - Our Institutional Experience with Review of Literature
}

\author{
Authors \\ Dr Buddha Kanaka Mahalakshmi ${ }^{1}$, Dr Jaya Kavya Nadiminti ${ }^{2}$, Dr Anantha Ramani \\ Pratha $^{3}$, Dr Sekuboyina Kiran Datta ${ }^{4}$, Dr Lakshmi Prasanna Garapati ${ }^{5}$ \\ ${ }^{1}$ Assistant Professor of Surgery, Andhra Medical College, Visakhapatnam, India \\ 2, 4,5 Junior Resident of Surgery, Andhra Medical College, Visakhapatnam, India \\ ${ }^{3}$ Associate Professor of Surgery, Andhra Medical College, Visakhapatnam, India \\ *Corresponding Author \\ Dr Anantha Ramani Pratha \\ Associate Professor of Surgery, Andhra Medical College, Visakhapatnam, India
}

\begin{abstract}
Introduction: Pancreatic and periampullary carcinomas include a group of malignant neoplasms arising in or near the ampulla of Vater or in the pancreas. Diagnosis, management and prognosis have improved considerably in the last few decades. The present study looks into the modes of presentation in patients with periampullary carcinoma, the different modalities of investigations, treatment along with the postoperative complications.

Materials and Methods: It is a retrospective, descriptive study including 25 patients of periampullary carcinoma studied over a period of one and half year from January 2017 to June 2018 in a tertiary care centre in Visakhapatnam. In the present study, age and sex distribution, site of tumour origin, histopathological variant, postoperative complications and other factors were evaluated. We have adopted the classical Whipple's Pancreaticoduodenectomy as the procedure for the treatment of operable periampullary cancers.
\end{abstract}

Results: The mean age of presentation was 52.6 years. The male to female ratio was 2.5:1. The most common site of tumour origin was the head of pancreas. Majority were well differentiated adenocarcinomas. The most common postoperative complications were pancreatic leak and wound infection $(14.2 \%)$.

Conclusion: Patients with pancreatic and periampullary cancer represent a difficult and challenging group to treat. Pancreaticoduodenectomy is a standard procedure that has been adopted for the treatment of this group of cancers. Resection should be performed by experienced surgeons to minimize morbidity and mortality. Though these patients have a poor prognosis, with proper staging, good patient selection and appropriate management, there is improved survival and wellbeing of these patients.

\section{Introduction}

Periampullarytumours can arise from pancreatic, biliary, ampullary and duodenal tissues. The incidence of periampullary cancer is relatively low in comparison to breast, lung and colorectal cancers. However, as a result of their lethal nature, they are a major cause of mortality. Diagnostic modalities, management options and prognosis for 
periampullary carcinoma have improved considerably in the last few decades. ${ }^{1,2}$

Surgical resection offers the only chance of cure to these patients. ${ }^{3}$

\section{Aims}

- To study the clinical profile of patients with periampullary malignancies.

- To determine the most common histopathological type.

- To review the postoperative complications after Classical Whipple's Pancreaticoduodenectomy.

\section{Materials and Methods}

The study is retrospective conducted at King George Hospital, Visakhapatnam in the period of January 2017 to June 2018. A total of 25 cases with periampullary cancers at different stages were studied. Variables studied were age, sex, preoperative total serum bilirubin, CA 19-9 and ALP, preoperative biliary stenting, stage of disease, operative procedure, site of tumour origin and postoperative complications.

\section{Inclusion Criteria}

Patients diagnosed with periampullary carcinoma by CECT, ERCP or endoscopy.

\section{Exclusion Criteria}

Patients with pancreatitis, carcinoma exocrine and endocrine pancreatic tissue were excluded.

Patients with major comorbidities, such as cardiac or renal diseases were excluded.

\section{Results}

Total number of patients was 25 , out of which 18 cases were male and female cases were 7 . Ratio was 2.5:1.

Mean age group was 52.6 $\pm 3.4 \mathrm{yrs}$.

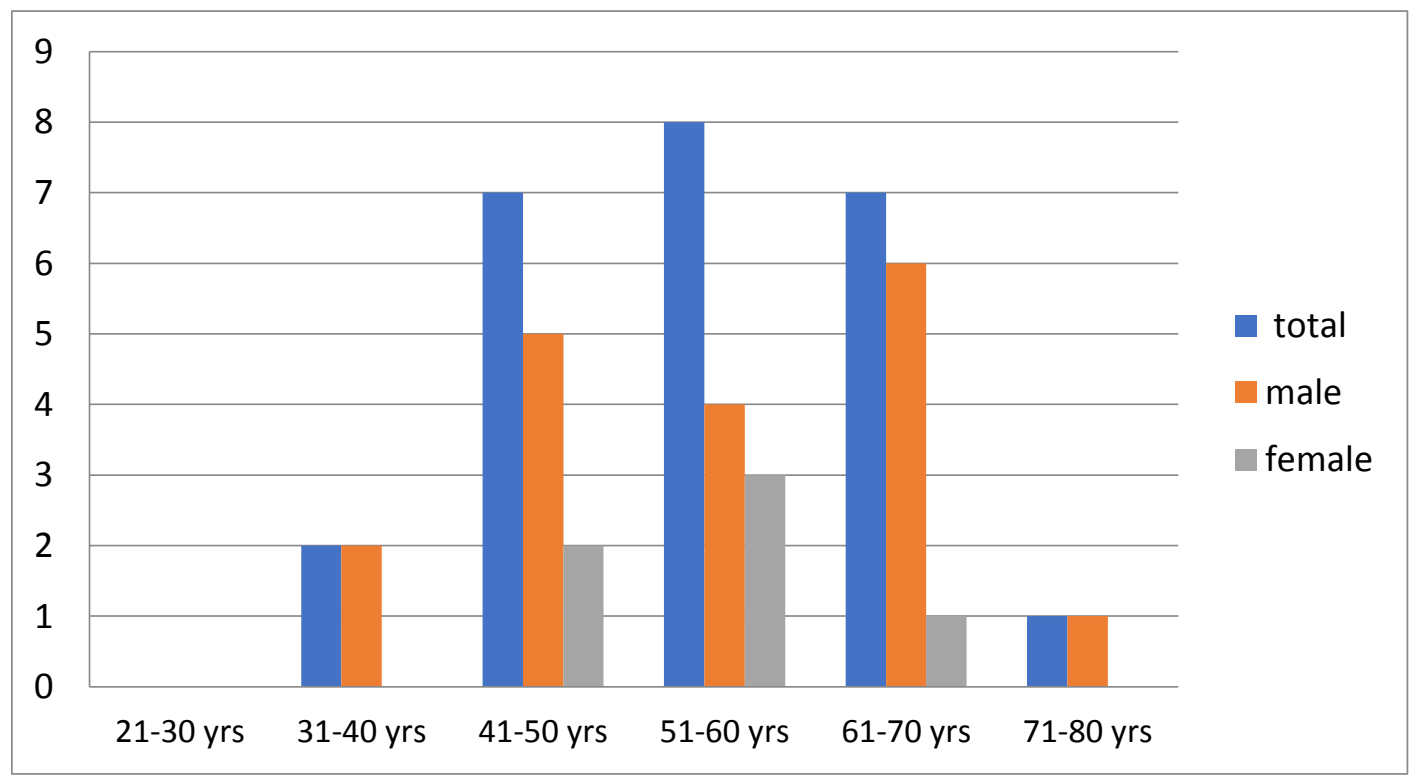

Chief complaints were jaundice, pain abdomen, vomiting and fever.

\begin{tabular}{|l|c|}
\hline Symptoms & Percentage \\
\hline Jaundice & $92 \%$ \\
\hline Vomiting & $40 \%$ \\
\hline Pain abdomen & $32 \%$ \\
\hline Anorexia & $32 \%$ \\
\hline Weight loss & $28 \%$ \\
\hline Fever & $20 \%$ \\
\hline
\end{tabular}


11 patients presented with preoperative total bilirubin greater than $10 \mathrm{mg} / \mathrm{dl}$. 14 members of the patients had preoperative ALP levels greater than 140U/L. 10 people presented with preoperative serum CA19-9 level more than 100U/L.

Preoperative stenting was done in 8 patients.

Other investigations were performed as shown in the table below.

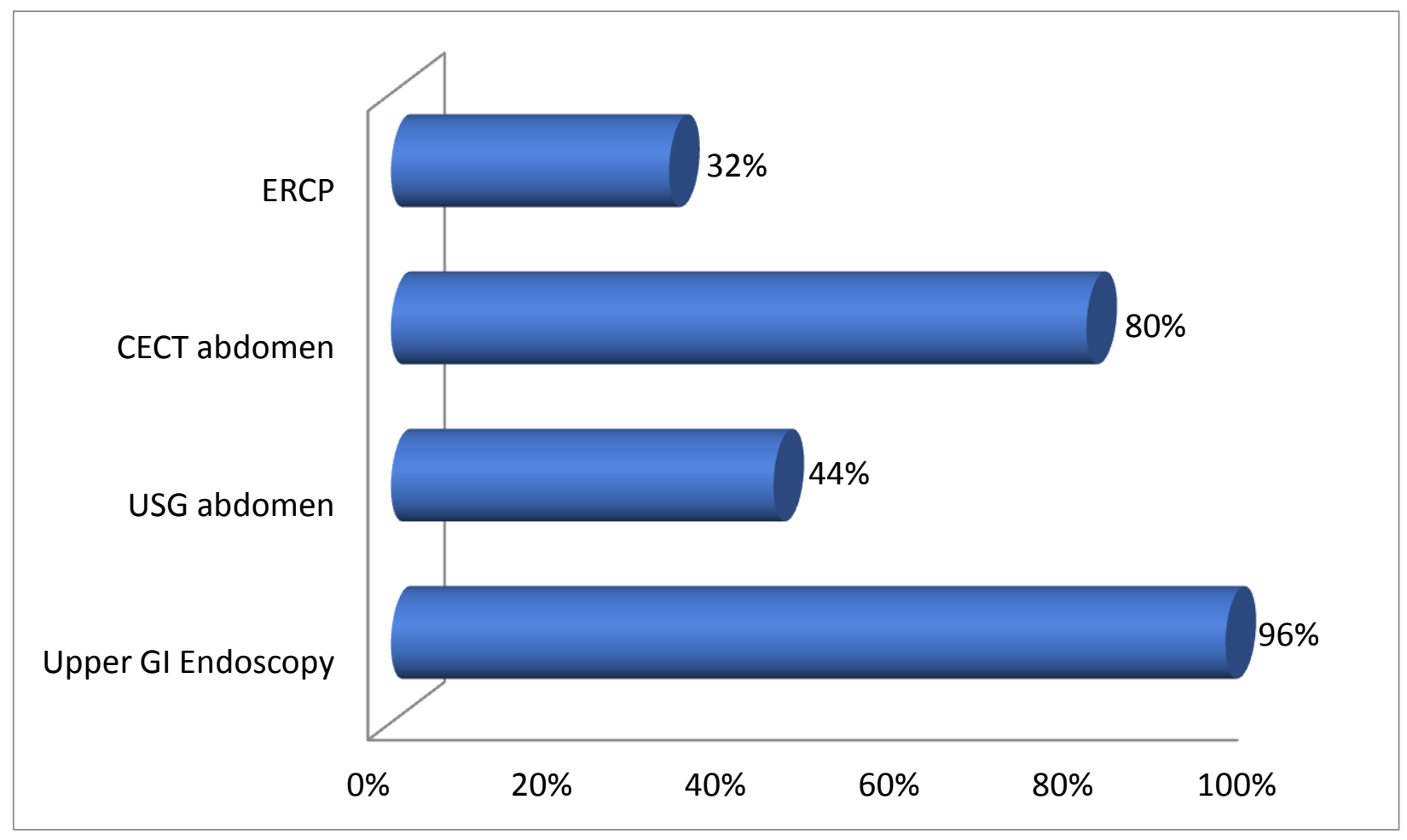

Majority of the patients were diagnosed with stage II disease.

Out of the 25 patients, 21 patients underwent Whipple's pancreaticoduodenectomy. Three patients underwent palliative bypass procedures such as choledochojejunostomy due to non resectability of the tumour. One patient was sent for palliative radiotherapy. 


\section{Whipple's \\ pancreaticoduodenectomy \\ 21 cases \\ Double Bypass \\ 2 cases}

\section{Triple Bypass \\ 1 case}

Palliative Radiotherapy

1 case

Postoperative Complications

Some type of complication occurred in $45.8 \%$ of the patients.

In Hospital mortality for postoperative cases was 08\% (2 patients).

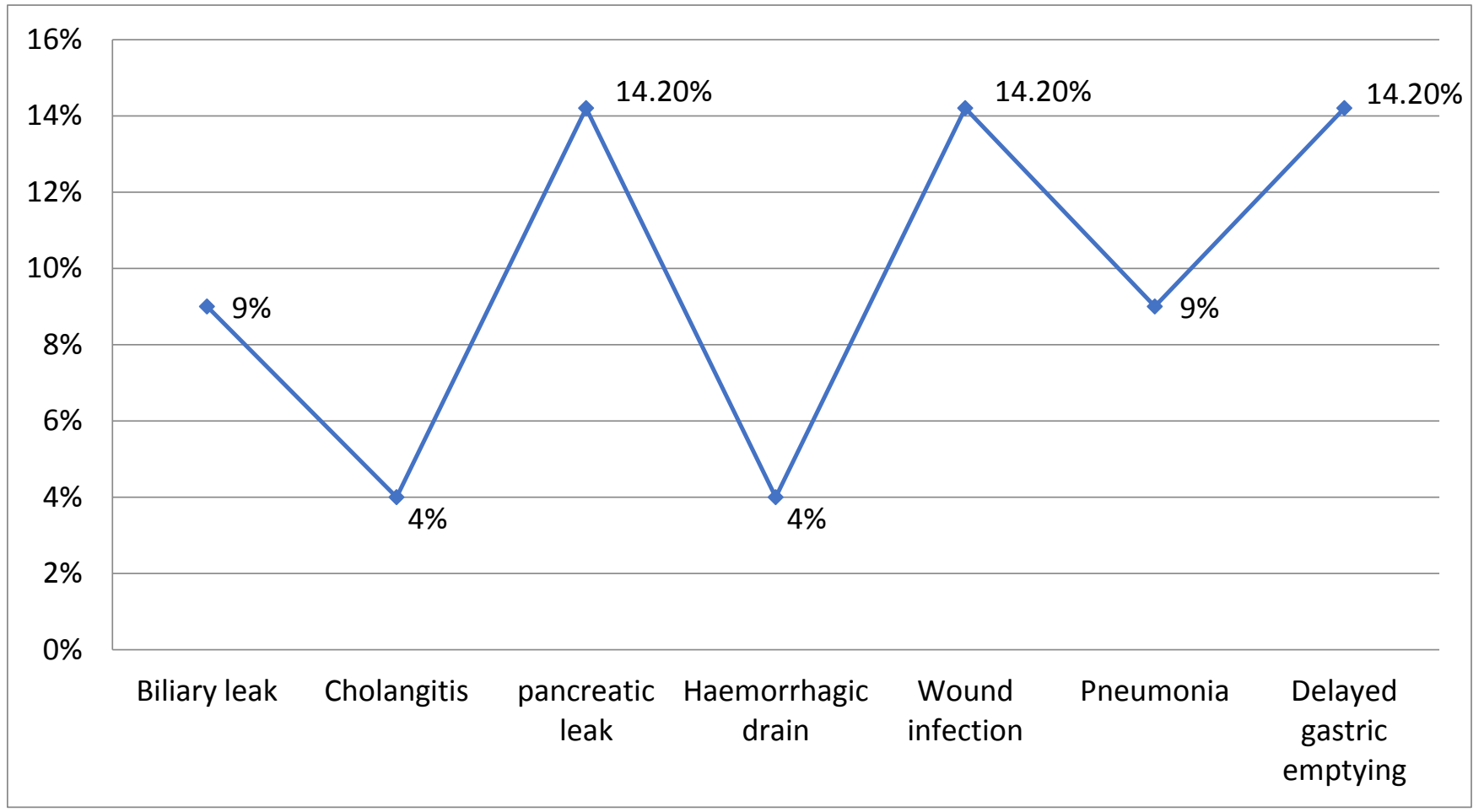




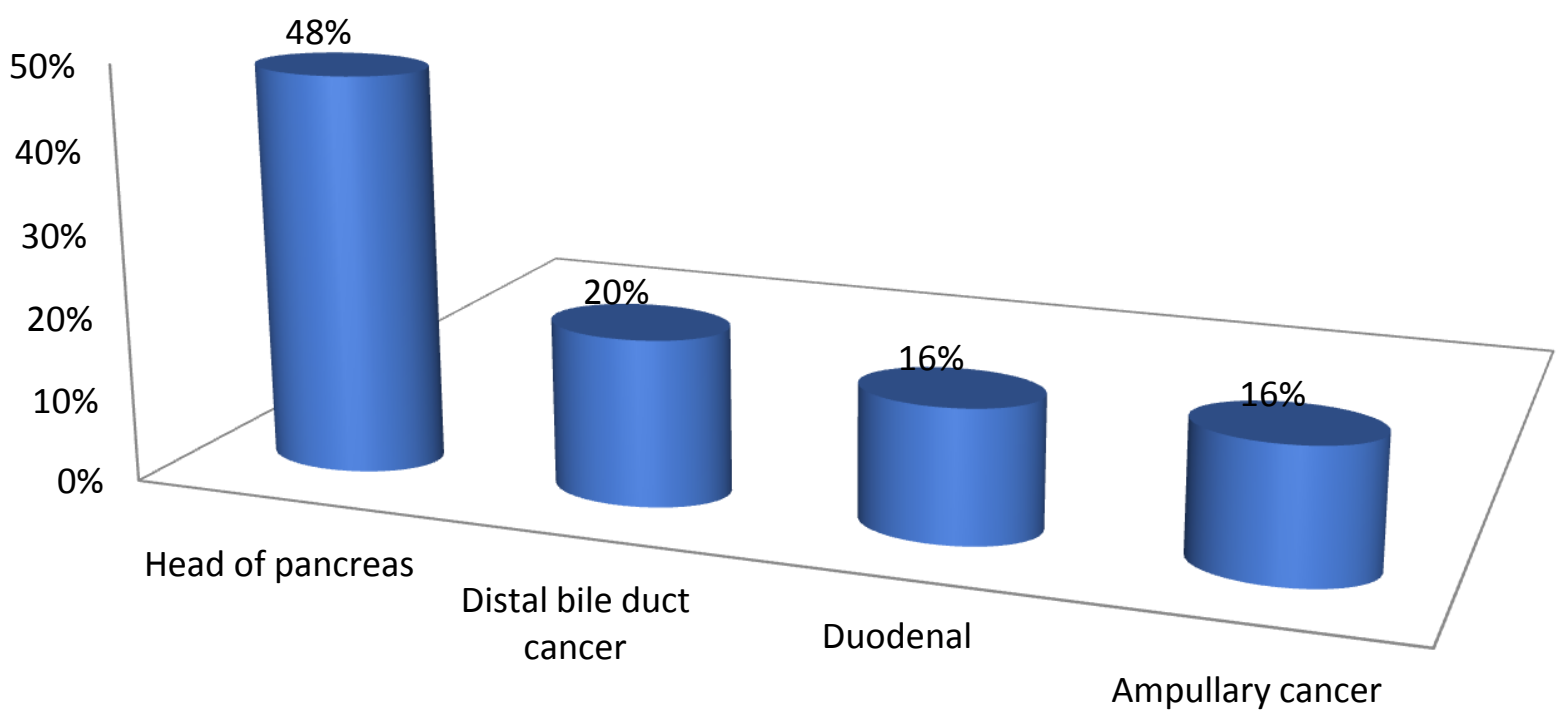

Postoperative biopsy showed predominance of pancreatic cancer (48\%), followed by distal bile duct cancer $(20 \%)$.

Histopathology showed all specimens to be adenocarcinomas. One patient had neuro endocrine component along with adenocarcinoma. Majority of the tumours were well differentiated $(52 \%)$.

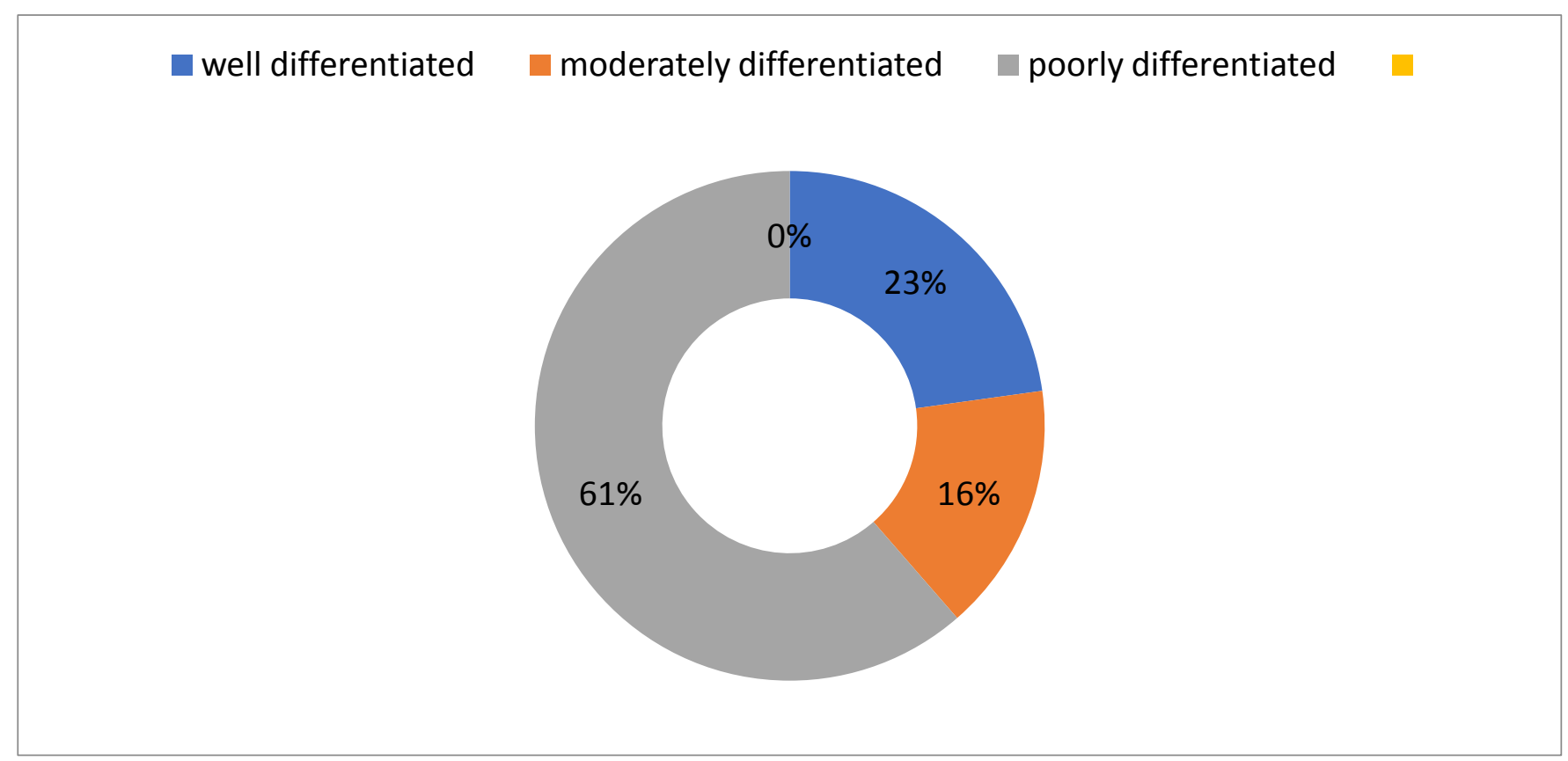

\section{Review of literature}

In the present study, the average age of patients was 52.6years comparable with studies conducted by JON R. COHEN et $\mathrm{al}^{4}$, Xun Wang et $\mathrm{al}^{5}$, TaxiarchisBotsis et $\mathrm{al}^{6}$.
There is a male preponderance similar to studies by Carlos Chan et $\mathrm{al}^{7}$ and Woo-Song Ha et $\mathrm{al}^{8}$. 


\begin{tabular}{|l|c|c|c|c|}
\hline Symptoms & ${\text { Tarazi et } \mathrm{al}^{9}}$ & Robertson et al $^{10}$ & ${\text { Shanti et } \mathrm{al}^{11}}^{11}$ & Present study \\
\hline Jaundice & $78 \%$ & $93 \%$ & $76 \%$ & $92 \%$ \\
\hline Loss of appetite & $70.6 \%$ & $\mathrm{NM}$ & $73 \%$ & $32 \%$ \\
\hline Pain abdomen & $57.9 \%$ & $47 \%$ & $46 \%$ & $32 \%$ \\
\hline
\end{tabular}

\section{Diagnostic modalities}

Ultrasound is the first investigation used in our study. It and could accurately diagnose $44 \%$ of the cases.

EUS is significantly more sensitive, specific, and accurate than helical CT for evaluation of the periampullary mass. Parameters evaluated included tumour size, lymphnode metastases, and major vascular invasion. They are helpful in preoperative staging of the disease.

Sensitivity of Diagnostic Modalities

\begin{tabular}{|l|c|c|c|}
\hline Test & Woo-Song Ha et al (1980) $^{8}$ & Malla BR, et al(2017) $^{12}$ & Current Study \\
\hline Upper GI Endoscopy & $58.1 \%$ & $85.41 \%$ & $96 \%$ \\
\hline USG abdomen & $87.5 \%$ & $79.16 \%$ & $44 \%$ \\
\hline CECT abdomen & $\mathrm{NM}$ & $47.91 \%$ & $80 \%$ \\
\hline ERCP & $85.7 \%$ & $25 \%$ & $32 \%$ \\
\hline
\end{tabular}

Treatment Modalities

Classical Whipple's Pancreaticoduodenectomy is the standard resectional surgical procedure being done in our department for operable cases. It was done in 21 cases.Palliative surgeries include hepaticojejunostomy, choledochojejunostomy and cholecystojejunostomy to relieve obstructive jaundice; gatrojejunostomy, gastrostomy are used to relieve gastric outlet obstruction. Chemical splanchinectomy can be used to relieve pain.

In this study we have done palliative gastrojejunostomy and choledochojejunostomy for cases. One case was sent for palliative radiotherapy.

Location of tumour

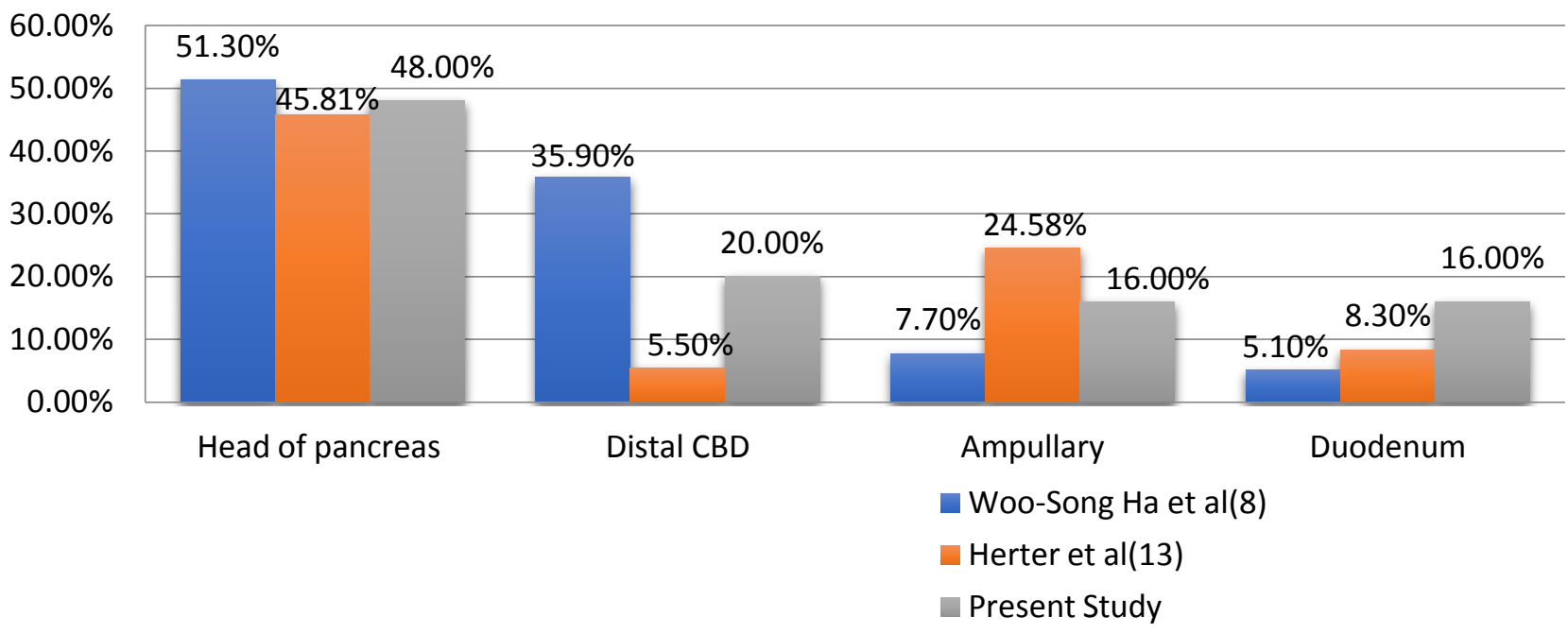


Tumour Differentiation

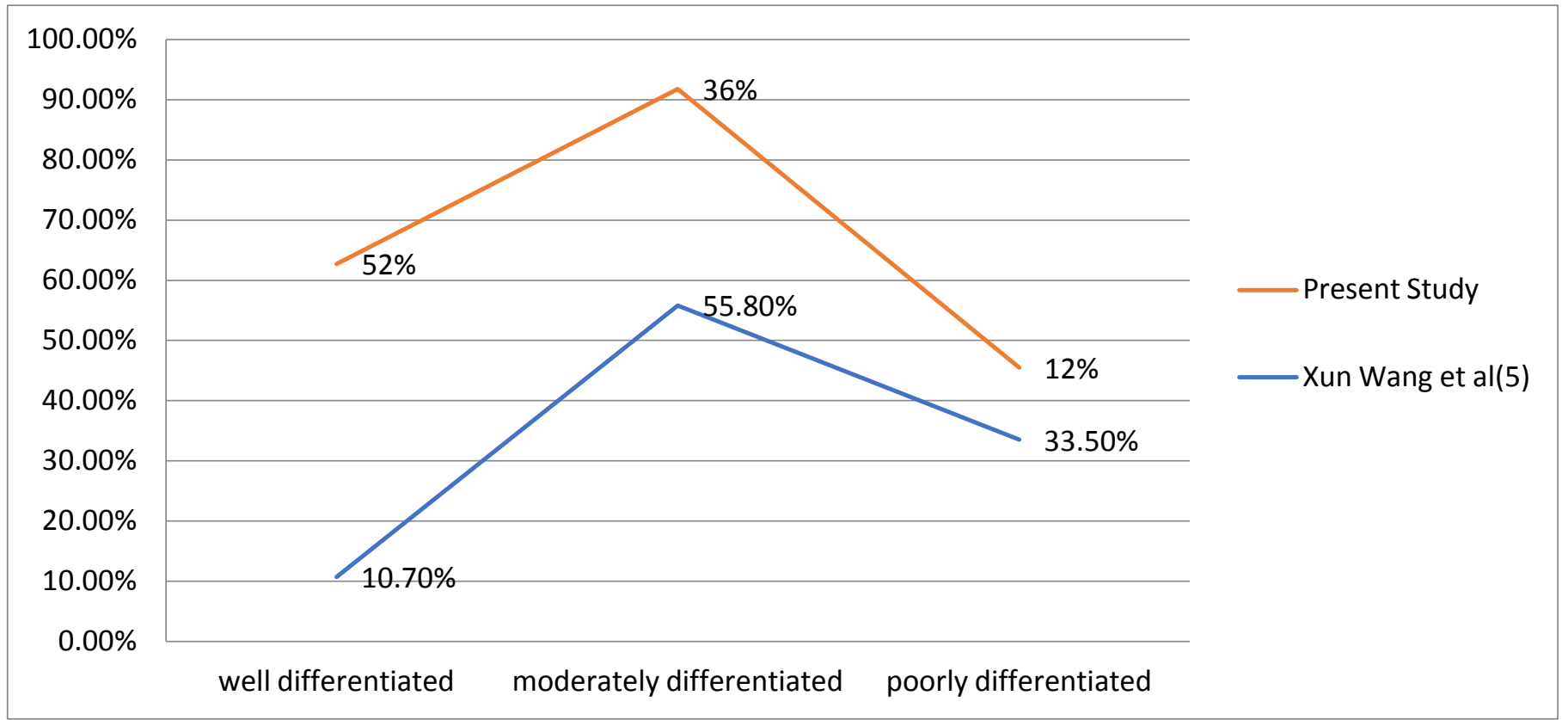

Postoperative Complications:

\begin{tabular}{|l|c|c|c|}
\hline Postoperative Complications & ${\text { Saraee et } \mathrm{a}^{14}}$ & Gupta et al $^{15}$ & Current study \\
\hline Delayed gastric emptying & $32.9 \%$ & $35.29 \%$ & $14.2 \%$ \\
\hline Biliary leak & $2.9 \%$ & $13.72 \%$ & $9 \%$ \\
\hline Pancreatic leak & $0 \%$ & $17.64 \%$ & $14.2 \%$ \\
\hline Cholangitis & $0 \%$ & $\mathrm{NM}$ & $4 \%$ \\
\hline Haemorrhagic drain & $7.1 \%$ & $19.6 \%$ & $4 \%$ \\
\hline Wound infection & $17.1 \%$ & $39.21 \%$ & $14.2 \%$ \\
\hline Pneumonia & $10 \%$ & $23.52 \%$ & $9 \%$ \\
\hline
\end{tabular}

In hospital moratlity was $08 \%$.

\section{Conclusion}

Patients with pancreatic and periampullary cancer represent a difficult and challenging group to treat. Pancreaticoduodenectomy is a standard procedure that has been adopted for the treatment of this group of cancers.

Resection should be performed by experienced surgeons to minimize morbidity and mortality.

Although traditionally patients with these diseases had a dismal prognosis, proper staging and patient selection have led to improved results.

Early diagnosis is crucial for resectability to improve survival rates.

\section{References}

1. Jagannath $P$, Shirkande $S$, Current options in the diagnosis and management of periampullary carcinoma. Indian $\mathbf{J}$ surg.2003;65;347-53.

2. Jakhmola CK, Kumar A. Whipple's pancreaticoduodenectomy : Outcomes at a tertiary care hospsital. Med J Armed Forces India. 2014;70:321-6.

3. Charles J, Yeo M, John L, Cameron MD. Pancreaticoduodenectomy with or without extended retroperitoneal lymphadenectomy for periampullary adenocarcinoma comparison of morbidity 
and mortality and short-term outcome.

Ann Surg. 1999;229(5):613-24.

4. J R Cohen, N Kuchta, N Geller, G T Shires, and $\mathrm{P}$ Dineen. Pancreaticoduodenectomy. A 40-year experience. Ann Surg. 1982 May; 195(5): 608-617.

5. Xun Wang, Jian Feng, Mingyi hen, ShouwangCai, JianjunLeng, Zhiwei Liu, Wenzhi Zhang. A comprehensive clinicopathological analysis and survival outcome of periampullary cancer following pancreatoduodenecomy. Int $\mathrm{J}$ Clin Exp Med 2016;9(8):15678-15688.

6. TaxiarchisBotsis, Valsamo KA, Gunnar Hartvigsen, Georges Hripisak and Chunhuaweng. Modeling prognostic factors in resectable pancreatic adenocarcinoma. Cancer inform 2009;7:281-91.

7. Carlos Chan, Miguel F. Herrera, Lorenzode La Garza, Leticia QuintanillaMartinez, Florenciavargas-Vorackova et al. Clinical behaviour and prognostic factors of periampullary adenocarcinoma. Annals of Surg 1995;222(5):632-37.

8. Woo Song Ha, and JinPok Kim. A clinical study of periampullary carcinoma. Cancer Research and Treatment, 1980;12(1):7990.

9. Tarazi RY, Hermann RE, Vogt DP, Hoerr SO, Esselstyn CB Jr, et al. Results of surgical treatment of periampullary tumours: A thirty-five year experience. Surgery.1986;100;716-21.

10. Robertson JFR, Imrie CW, Hole DJ, Carter DC, Blumgart LH. Management of periampullary carcinoma. $\mathrm{Br} \quad \mathrm{J}$ Surg. 1987;74:816-9.

11. VissaShanthi et al. Pancreatobiliary versus intestinal type of histological differentiation: A comparitive study with histomorphological prognostic factors in periampullary carcinoma. Int J Med Res Health Sci.2013;2(3):380-387.
12. Bala Ram Malla, Gabriel Rodrigues. Periampullary carcinoma: An audit of an institutional experience with literature review. Malla BR, et al. SurgChron 2017; 22(1):4-6.

13. Frederic P. Herter, Avram M. Copperman, Thomas N. Ahlborn, and Charles Antinori. Surgical Experience with pancreatic and periampullary cancer. Ann Surg. 982 Mar;195(3):274-281.

14. Amir Saraee et al. Whipple procedure: a review of a 7-year cinical experience in a referral center for hepatobiliary and pancreas diseases. World journal of oncology (2015)13:98.

15. Gupta et al. Whipple's procedure: Yesterday and today. Int $\mathbf{J}$ Hepatobiliary Pancreat Dis 2015;6:1-5. 